\title{
Electrocardiogram Manifestations in Traumatic Right-sided Pneumothorax: Case Report
}

\author{
Eduardo Lapa Santos ${ }^{1 *}$, Eduardo Alberto de Castro Roque ${ }^{2}$, Bianca Dadalto ${ }^{2}$, Luca T Dompieri ${ }^{3}$, Maria Amellia \\ Aquino $^{3}$ and Renato D Lopes ${ }^{4}$
}

${ }^{1}$ Cardiology Unit, Hospital das Clinicas, Universidade Federal do Pernambuco, Brazil

${ }^{2}$ Hospital Metropolitano, Brazil

${ }^{3}$ Universidade Federal de Pernambuco, Brazil

${ }^{4}$ Division of Cardiology, Duke University Medical Center, USA

Submission: March 10, 2018; Published: May 09, 2018

*Corresponding author: Eduardo Lapa Santos, Cardiology Unit, Hospital das Clinicas, Universidade Federal do Pernambuco, Av. Prof. Moraes Rego, 1235 - Cidade Universitária, Recife -PE, 50670-901, Brazil, Tel: +55 81 996864444; Email: eduardolapa@gmail.com

\section{Abstract}

This report describes a case of a patient with right-sided pneumothorax presenting with classic electrocardiographic findings such as low voltage, extreme axis deviation to the right and tall R-wave in V1 suggesting right-ventricle overload. Drainage and aspiration were performed stabilizing the patient.

Keywords: Pneumothorax; Right-sided pneumothorax; Electrocardiography

\section{Introduction}

Electrocardiogram (ECG) findings such as right axis deviation, QSR abnormalities, T-wave inversions and ST-segment alterations [1] may lead to misdiagnosis of pneumothorax [2]. We describe a case of pneumothorax presenting with changes in ECG.

\section{Case Report}

A 74-year-old male was admitted to the emergency department with chest pain 72 hours after a fall. The patient

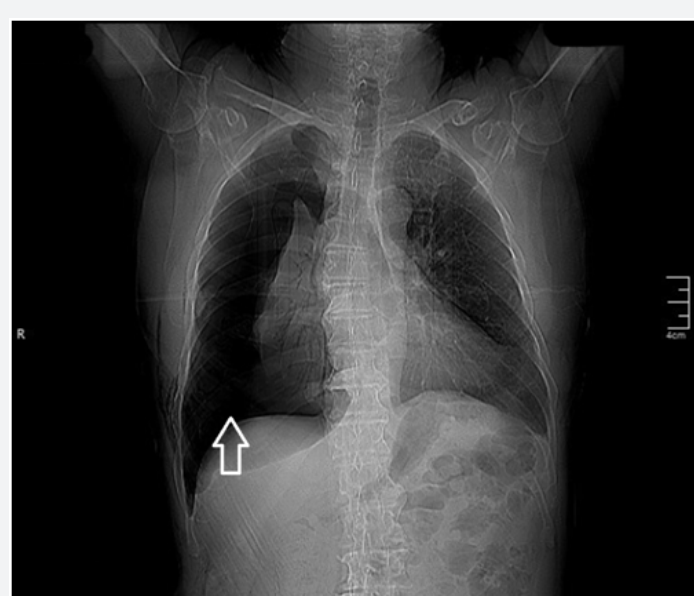

Figure 1: X-ray showing the fractures and right pneumothorax (arrow). had a past medical history of hypertension, hyperlipidemia and smoking (5pack/year).

At admission, the patient was in antalgic position and with shortness of breath. Examination revealed blood pressure of $148 / 90 \mathrm{mmHg}$, cardiac frequency of 66beats/min, oxygen saturation of $88 \%$ and decreased breath sounds at right hemithorax.

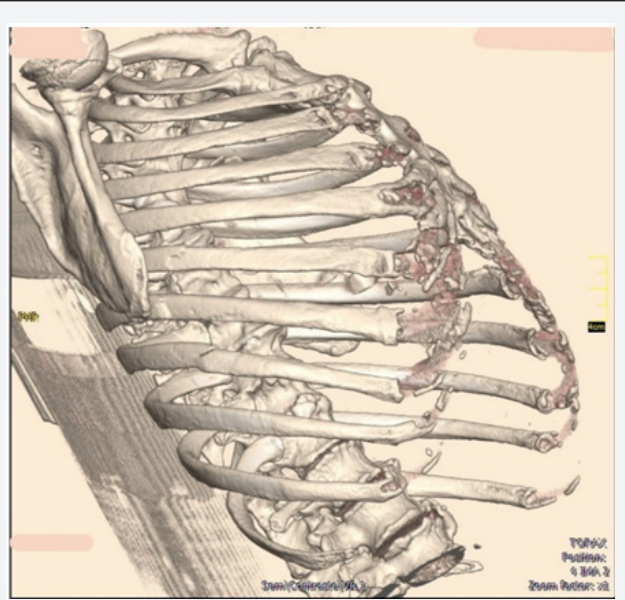

Figure 2: 3D reconstruction Computed Tomography showing the fractures. 


\section{Journal of Cardiology \& Cardiovascular Therapy}

Admission X-ray and computed tomography showed fracture at the sixth, seventh and eighth right costal arches with significant right pneumothorax (Figure 1 \& 2). ECG showed low voltage, extreme axis deviation to the right and tall R-wave in V1 suggesting right-ventricle overload (Figure 3).

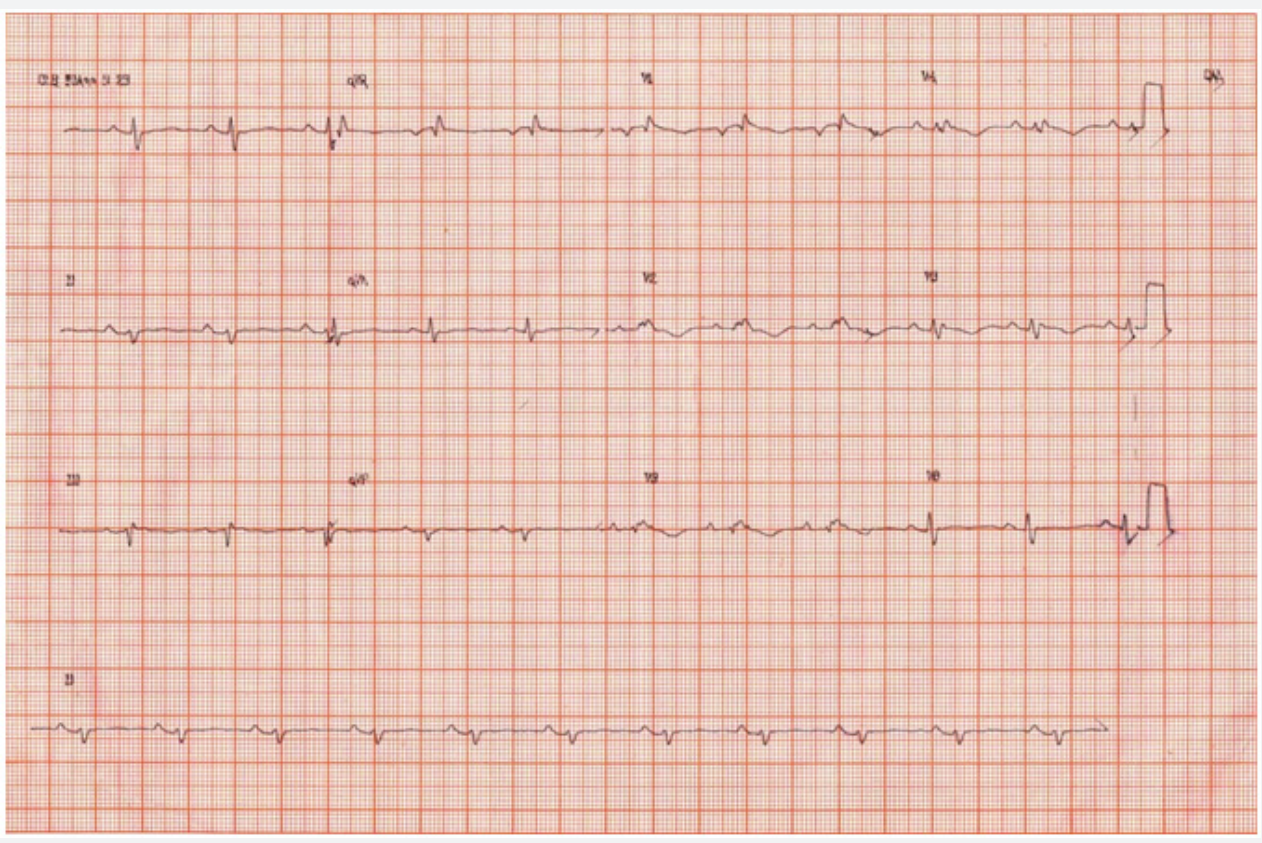

Figure 3: Admission electrocardiogram -low voltage, extreme axis deviation to the right and tall R-wave in V1.

Drainage and continuous aspiration were performed for 48 ECG, except for early repolarization on lateral leads (Figure 4). hours; discharge after 72 hours of hospitalization and normal

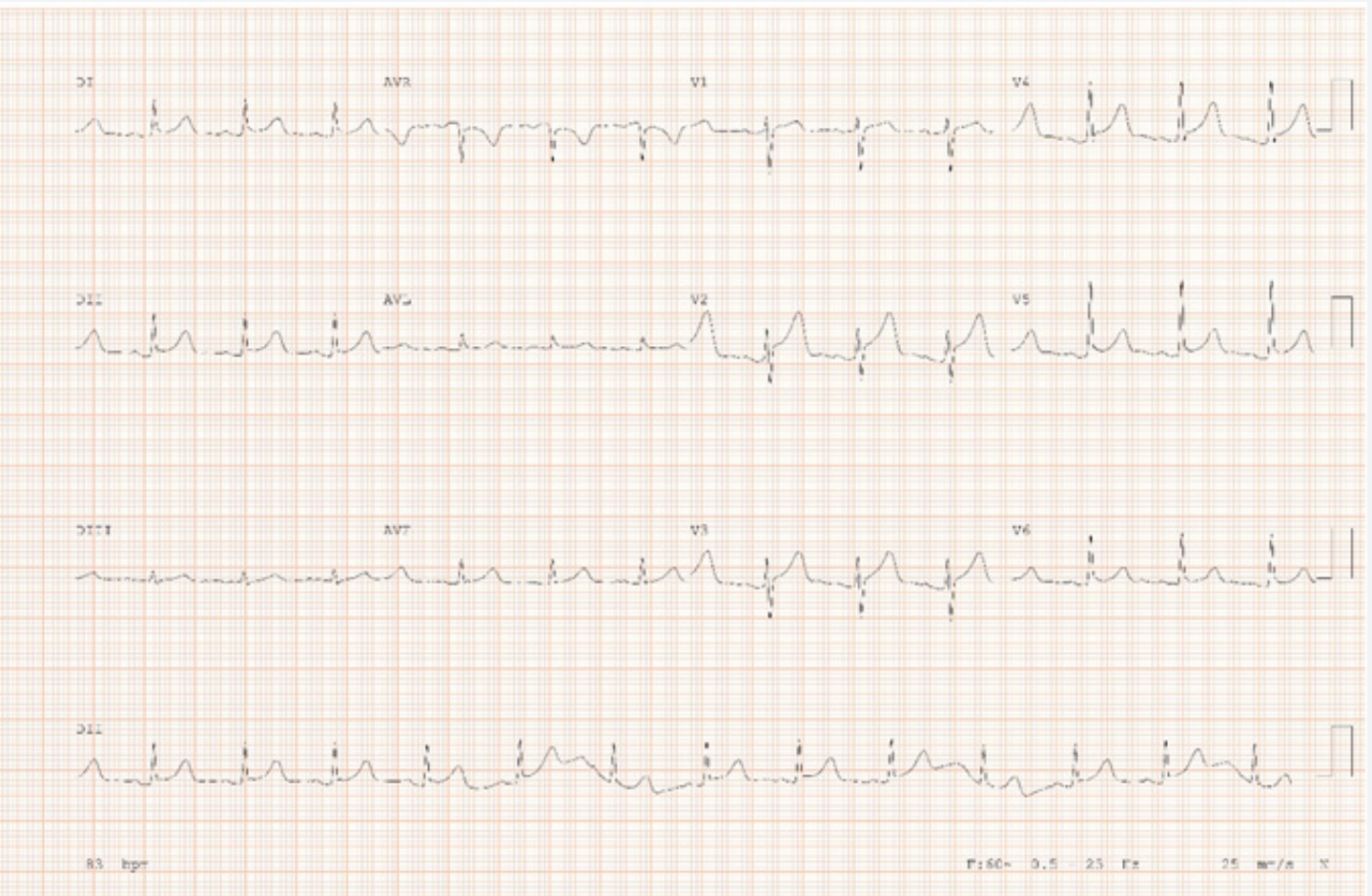

Figure 4: Discharge electrocardiogram -normal ECG, except for early repolarization on lateral leads. 


\section{Discussion}

The main ECG findings in pneumothorax cases include decreased QRS complex amplitude, QRS axis deviation, electrical alternans, reduced precordial R-wave voltage and precordial T-waves [3], being present in approximately $25 \%$ of the cases $[1,2]$. ST-segment deviations are also rare findings in patients with pneumothorax $[2,4]$.

The potential mechanisms behind the ECG changes in patients with pneumothorax are: the cardiac rotation around its axis; right ventricular dilatation due to increased pulmonary artery pressure; cardiac displacement; and air in the thoracic cavity acting as an insulator [3,5].

Depending on the size, amount of tension and the side involved on pneumothorax, the magnitude of ECG changes can vary substantially [3]. In left-sided pneumothorax, the most common findings include abnormal axis deviation and T-wave inversion [2]. Right-sided often include reduced QRS voltage and QRS axis changes [3].

Krenke et al. [2] showed that in right-sided pneumothorax the QRS axis deviation is mainly to the right without exceeding $30 \mathrm{o}$ and the QRS amplitude in V5 and V6 leads is increased [2].
However, in the case described, there is an extreme axis deviation to the right and decreased voltage in all leads, including V5-V6.

\section{Conflict of Interest}

The authors certify that they have no affiliations with or involvement in any organization or entity with any financial interest, or non-financial interest in the subject matter or materials discussed in this manuscript.

\section{References}

1. Alzghoul B, Innabi A, Shanbhag A, Chatterjee K, Amer F, et al. (2017) Iatrogenic right-sided pneumothorax presenting as ST-segment elevation: a rare case report and review of literature. Case Reports Crit Care 2017: 3291751.

2. Krenke R, Nasilowski J, Przybylowski T, Chazan R (2008) Electrocardiographic changes in patients with spontaneous pneumothorax. J Physiol Pharmacol 59(Suppl 6): 361-373.

3. Pollack ML (2006) ECG manifestations of selected extracardiac diseases. Emerg Med Clin North Am 24(1): 133-143.

4. Shiyovich A, Vladimir Z, Nesher L (2011) Left spontaneous pneumothorax presenting with ST-segment elevations: a case report and review of the literature. Hear Lung 40(1): 88-91.

5. Yeom SR, Park SW, Kim YD, Ahn BJ, Ahn JH, et al. (2017) Minimal pneumothorax with dynamic changes in ST segment similar to myocardial infarction. Am J Emerg Med 35(8): 1210.e1-1210.e4.

\begin{tabular}{l} 
Your next submission with Juniper Publishers \\
will reach you the below assets \\
- Quality Editorial service \\
- Swift Peer Review \\
- Reprints availability \\
- E-prints Service \\
- Manuscript Podcast for convenient understanding \\
- Global attainment for your research \\
- Manuscript accessibility in different formats \\
( Pdf, E-pub, Full Text, Audio) \\
- Unceasing customer service \\
Track the below URL for one-step submission \\
https://juniperpublishers.com/online-submission.php \\
\hline
\end{tabular}

